This item was submitted to Loughborough's Research Repository by the author.

Items in Figshare are protected by copyright, with all rights reserved, unless otherwise indicated.

\title{
Responsive behaviour of galvanic anodes in concrete and the basis for its utilisation
}

PLEASE CITE THE PUBLISHED VERSION

http://www.sciencedirect.com/science/article/pii/S0010938X11003441

PUBLISHER

(C) Elsevier

VERSION

AM (Accepted Manuscript)

LICENCE

CC BY-NC-ND 4.0

REPOSITORY RECORD

Holmes, S.P., G.D. Wilcox, Peter J. Robins, Gareth K. Glass, and A.C. Roberts. 2019. "Responsive Behaviour of Galvanic Anodes in Concrete and the Basis for Its Utilisation". figshare. https://hdl.handle.net/2134/8942. 
This item was submitted to Loughborough's Institutional Repository (https://dspace.lboro.ac.uk/) by the author and is made available under the following Creative Commons Licence conditions.

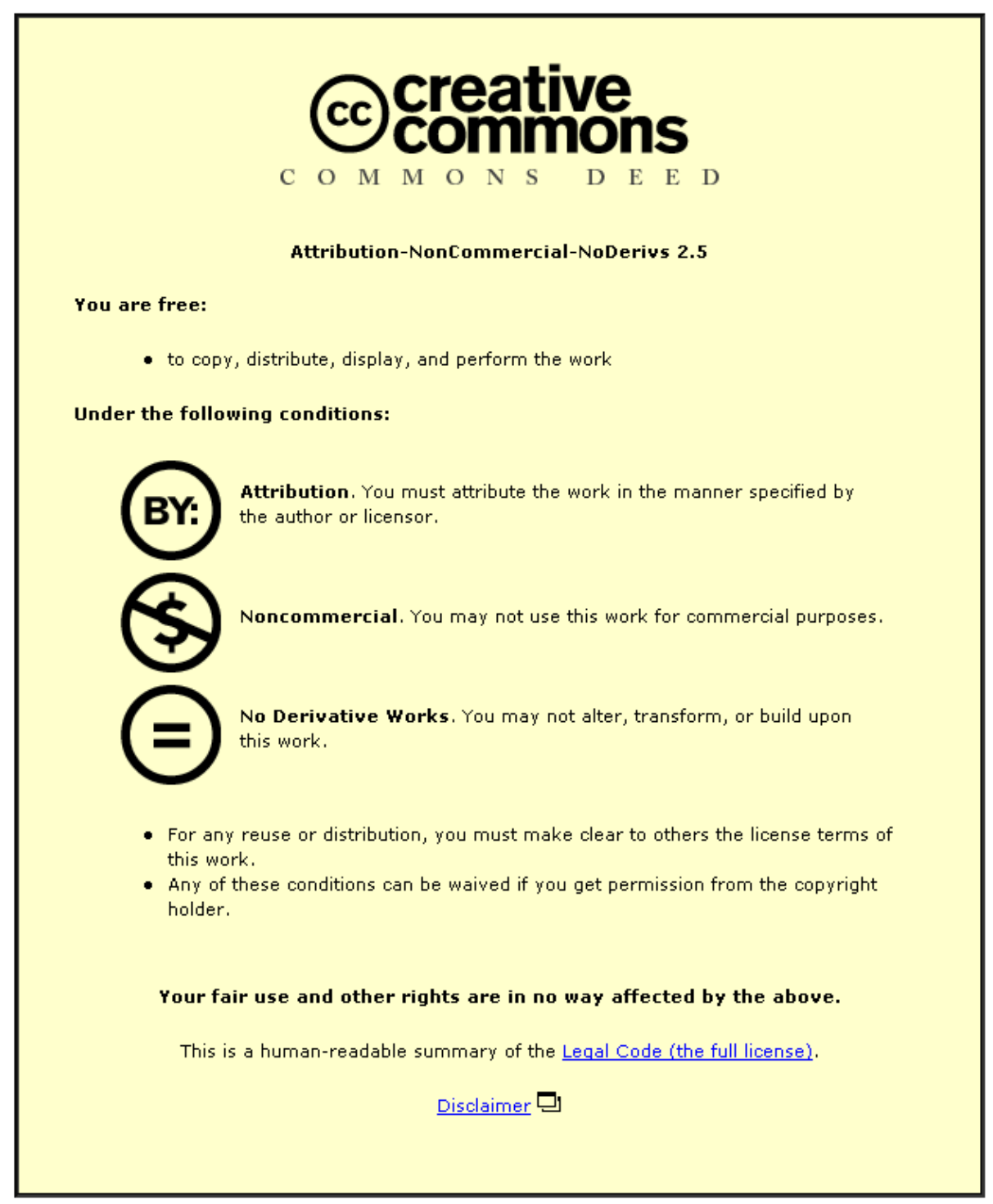

For the full text of this licence, please go to: http://creativecommons.org/licenses/by-nc-nd/2.5/ 


\title{
The Responsive Behaviour of Galvanic Anode Current in Concrete and the Basis for its Utilisation
}

\author{
*S.P. Holmes ${ }^{a}$, G.D. Wilcox ${ }^{a}$, P.J. Robins ${ }^{a}$, G.K. Glass ${ }^{b}$, A.C. Roberts ${ }^{b}$ \\ a Department of Materials/CICE, Civil \& Building Engineering, Loughborough University, \\ Leicestershire, LE11 3TU. s.p.holmes@lboro.ac.uk, Tel: +44(0)7816525419, Fax: +44(0)1509223982 \\ ${ }^{b}$ Concrete Preservation Technologies, The Sir Colin Campbell Building, University of Nottingham \\ Innovation Park, Triumph Road, Nottingham, NG7 2TU
}

*Corresponding author

\section{ABSTRACT}

In this study, a unique concrete specimen was used to analyse the response of embedded sacrificial zinc and steel anodes to rainfall and fluctuations in temperature. Current from the zinc and steel anodes increased when the environment was aggressive, showing that the required protection current depends on the present level of corrosion risk. A basis for using the 'responsive behaviour' of galvanic anodes is provided by the protective effects of pit re-alkalisation and $\mathrm{pH}$ maintenance. By contrast, protection based on achieving adequate polarisation inhibits the use of responsive behaviour and galvanic anodes might only deliver adequate polarisation in aggressive environments.

Keywords

A. Steel reinforced concrete

A. Steel

A. Zinc

B. Polarisation

C. Cathodic Protection

C. Passivity

\section{INTRODUCTION}

Electrochemical treatments are widely used in the mitigation of steel reinforcement corrosion. There is much debate within academia and industry regarding which treatment approach tackles the dominant factor affecting steel corrosion in concrete. It has been argued that adequately cathodically polarising the steel is the dominant protective effect. This is supported by the Pitting Potential/Re-passivation Potential hypothesis [1]. By contrast, it has been suggested that modifying the surface of the steel by raising the $\mathrm{pH}$ is the dominant protective effect, with reports that typical Impressed Current Cathodic Protection current densities are enough to halt corrosion when applied for long periods [2,3], or delay its onset in aggressive environments once the protective current has been removed [4,5]. These observations support the basis of the Pit Re-alkalisation/pH Maintenance hypothesis [6-8].

It has been reported that the current passed by galvanic anodes on site and in laboratory installations fluctuates depending on the local weather conditions and the time of year. The phenomena has been termed 'Responsive Behaviour' $[9,10]$. This brief study used a unique experimental design to investigate the effect of fluctuations in temperature and concrete moisture content on the current output of separate zinc and steel anodes encased in the same concrete 
sample. These results are then discussed with respect to the practical benefits of responsive behaviour and the protection criteria applied to steel in concrete.

\section{SAMPLE PREPARATION}

A concrete block, dimensions $600 \times 120 \times 120 \mathrm{~mm}$ was cast in November 2009. A 6:1 aggregate to cement mix with a 0.32 water to cement ratio was used. Two recesses were created on the top of the mould to house the anodes in a chloride $(\mathrm{NaCl})$ contaminated mortar which was prepared with a chloride content of $5 \%$ by weight of cement, using the same mix ratios as for the bulk concrete, but using sharp sand instead of an aggregate mix. A $20 \mathrm{~mm}$ rebar section was cast in centrally $30 \mathrm{~mm}$ from the base of the mould (Figure 1).The cylindrical anodes were cut to size $(65 \times 15 \mathrm{~mm})$ in order that their surface areas were the same $+/-5 \%$. Both were in a non-corroded state when they were cast into the mortar. Steel connections were made by riveting titanium wire into a drilled hole and painting over the connections with an epoxy primer. The anode currents were logged using a datalogger.
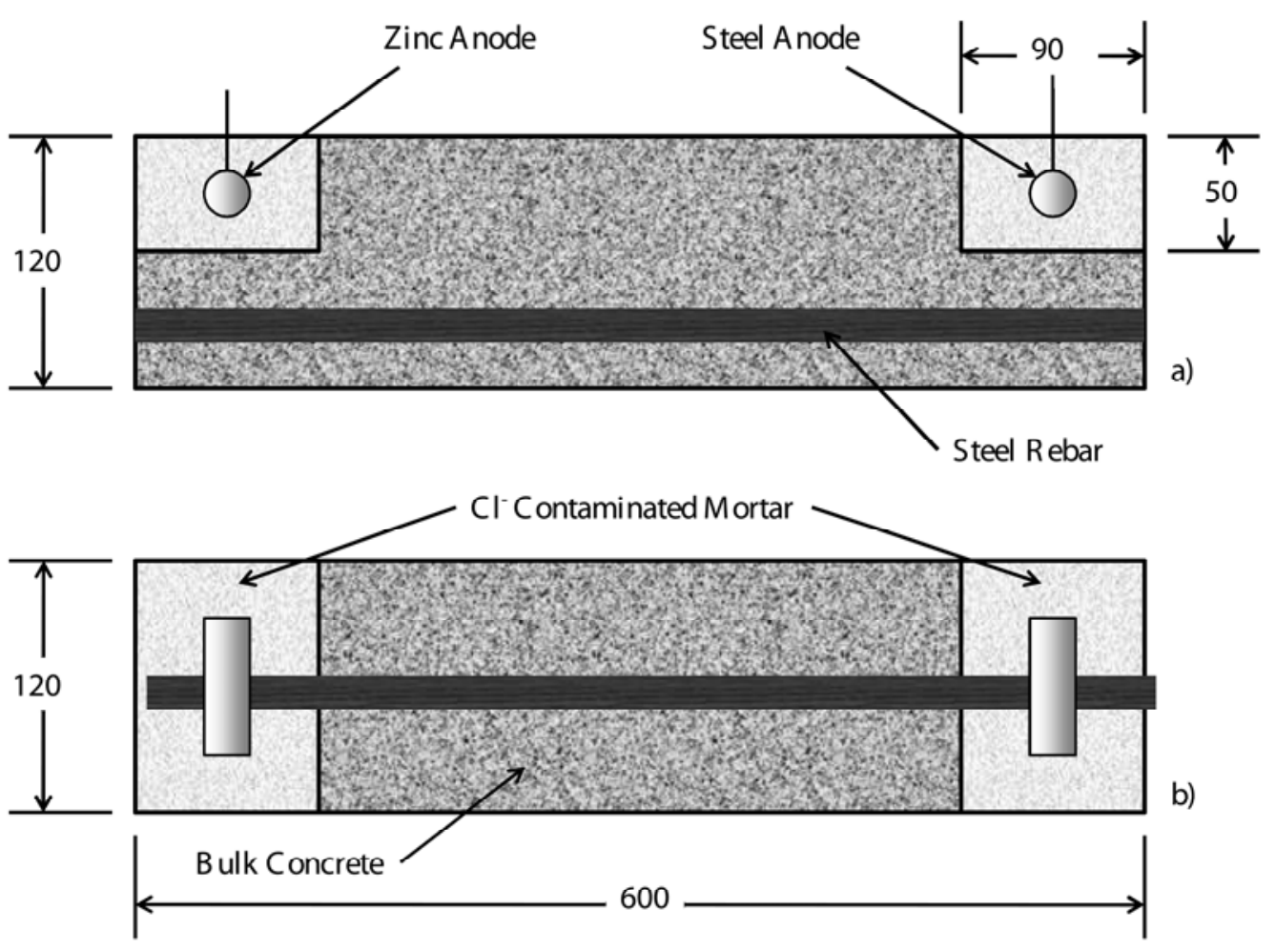

Figure 1. Embedded zinc and steel anode block; a) side elevation, b) plan elevation (All dimensions in $\mathrm{mm}$ ).

The block was de-moulded after 2 days and left to dry in the laboratory for 90 days before being placed outdoors. Temperature and rainfall data was obtained retrospectively from a public domain source.

\section{EXPERIMENTAL FINDINGS}

Figure 2 shows the current densities of the zinc and steel anodes, along with temperature and rainfall data. Both anodes were embedded in a chloride contaminated mortar but as the steel bar was installed in chloride-free mortar with significant cover it was not expected to be corroding. This test arrangement resulted in metal dissolution at the installed zinc and steel anodes providing a cathodic current to the steel bar. The large increase in the anode current densities on day 67 was as a result of rainfall after a period of dry weather. 

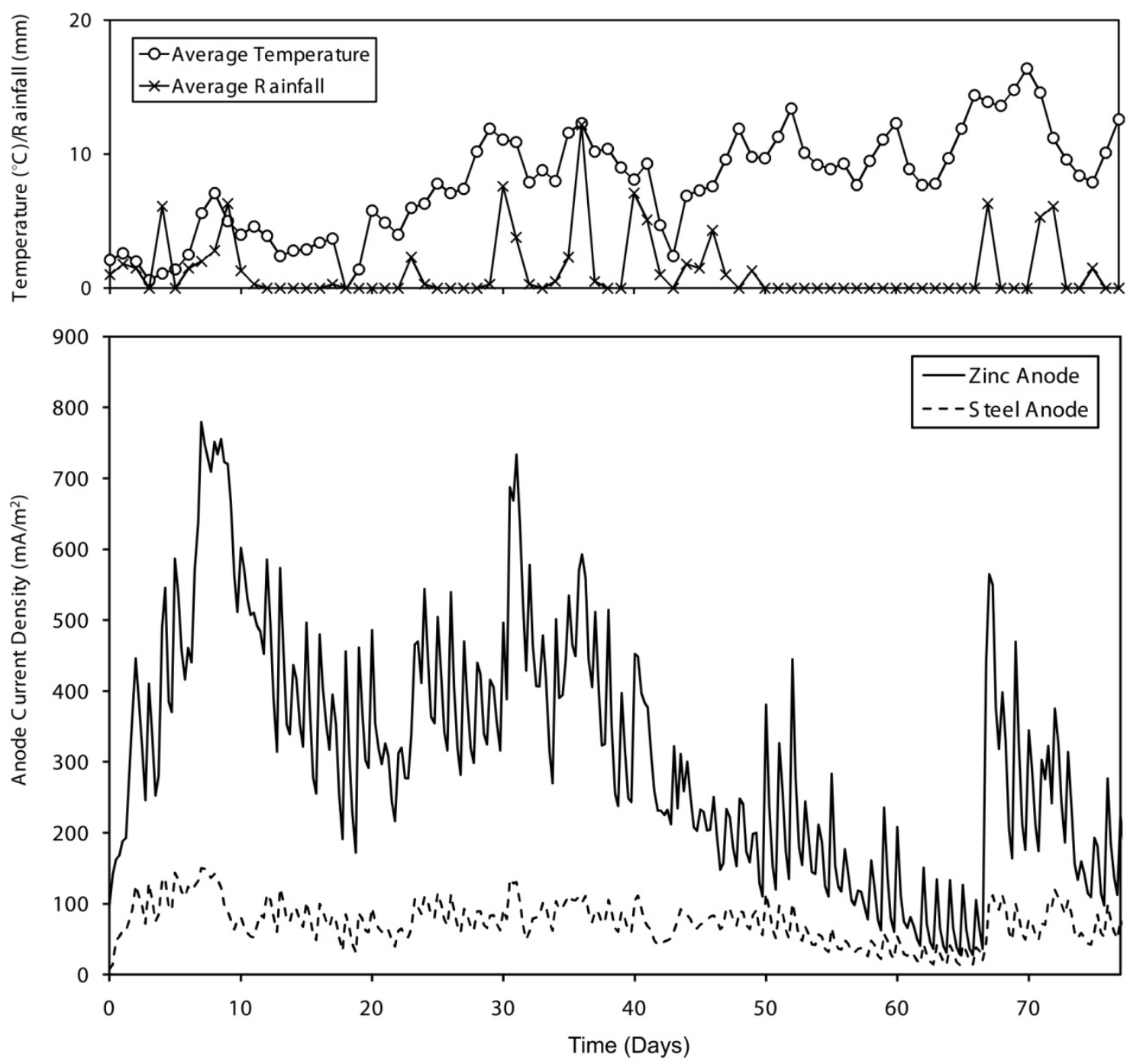

Figure 2. Steel anode current response to rainfall and changes in temperature.

The general decay in both zinc and anode current density is likely to be the result of a build up of corrosion products at the anode surface and a resulting increase in the resistance to current flow from the anodes.

Figure 3 is hourly data taken from the data used in Figure 2 and shows the anode response to rainfall in more detail. It can be seen that the zinc anode responded more quickly to the rapid environmental change. In contrast, Figure 4 shows the anode current densities on a day when no rain fell. It can be seen that in the absence of any 'shock' changes to the environment, the current outputs from both anodes follows the changes in daily temperature.

The ratio of the zinc and steel current densities (Figures 3 and 4 ) is a good indicator of the amount of protection offered to the steel by the zinc anode; when it is large, the zinc is offering more protective current than when the ratio is small. It can be seen that the protection offered to the steel increases when the environment becomes more aggressive. 


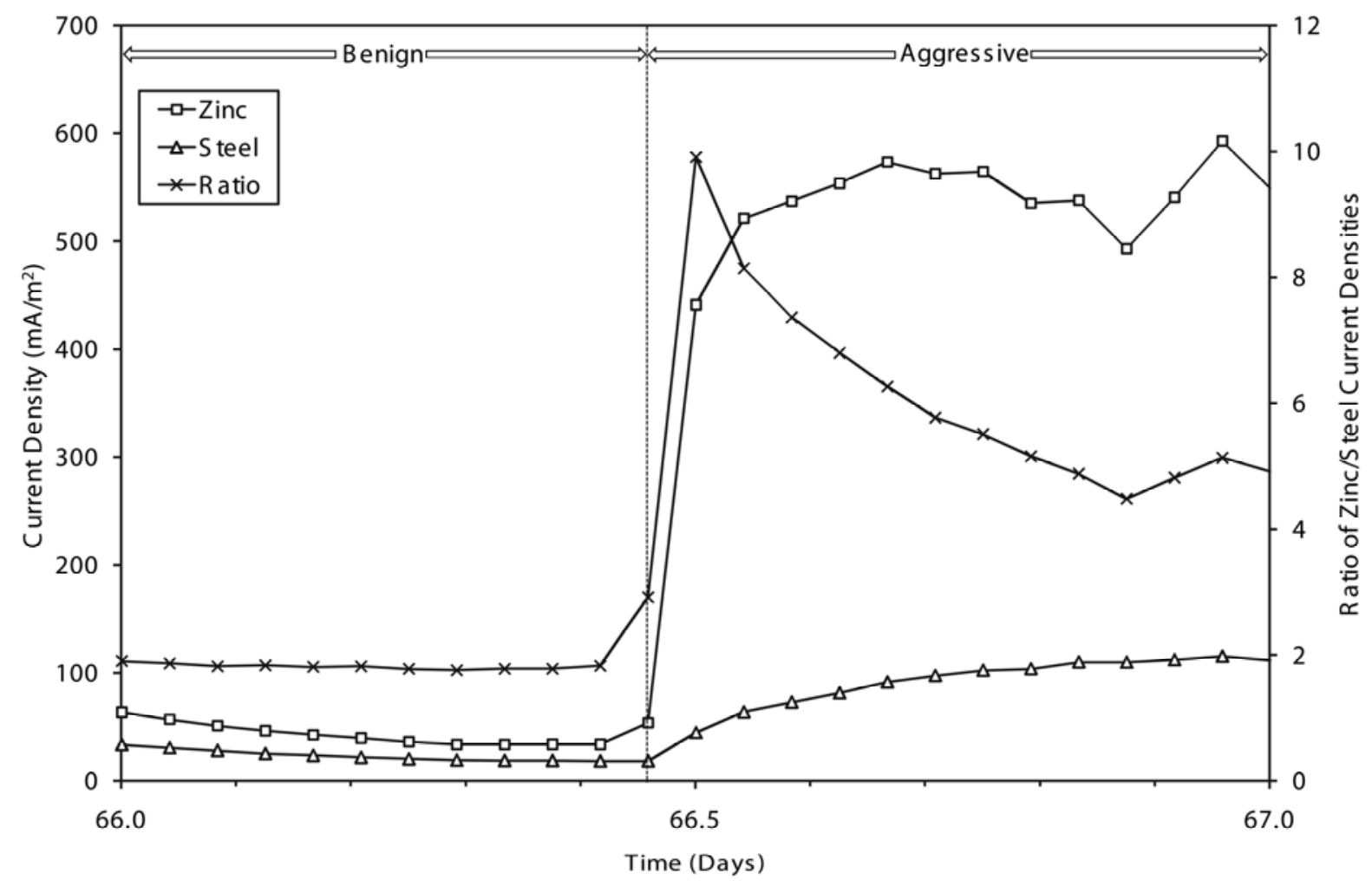

Figure 3. The zinc and steel anode current density response to sudden rainfall and the resulting effect on the protective ratio.

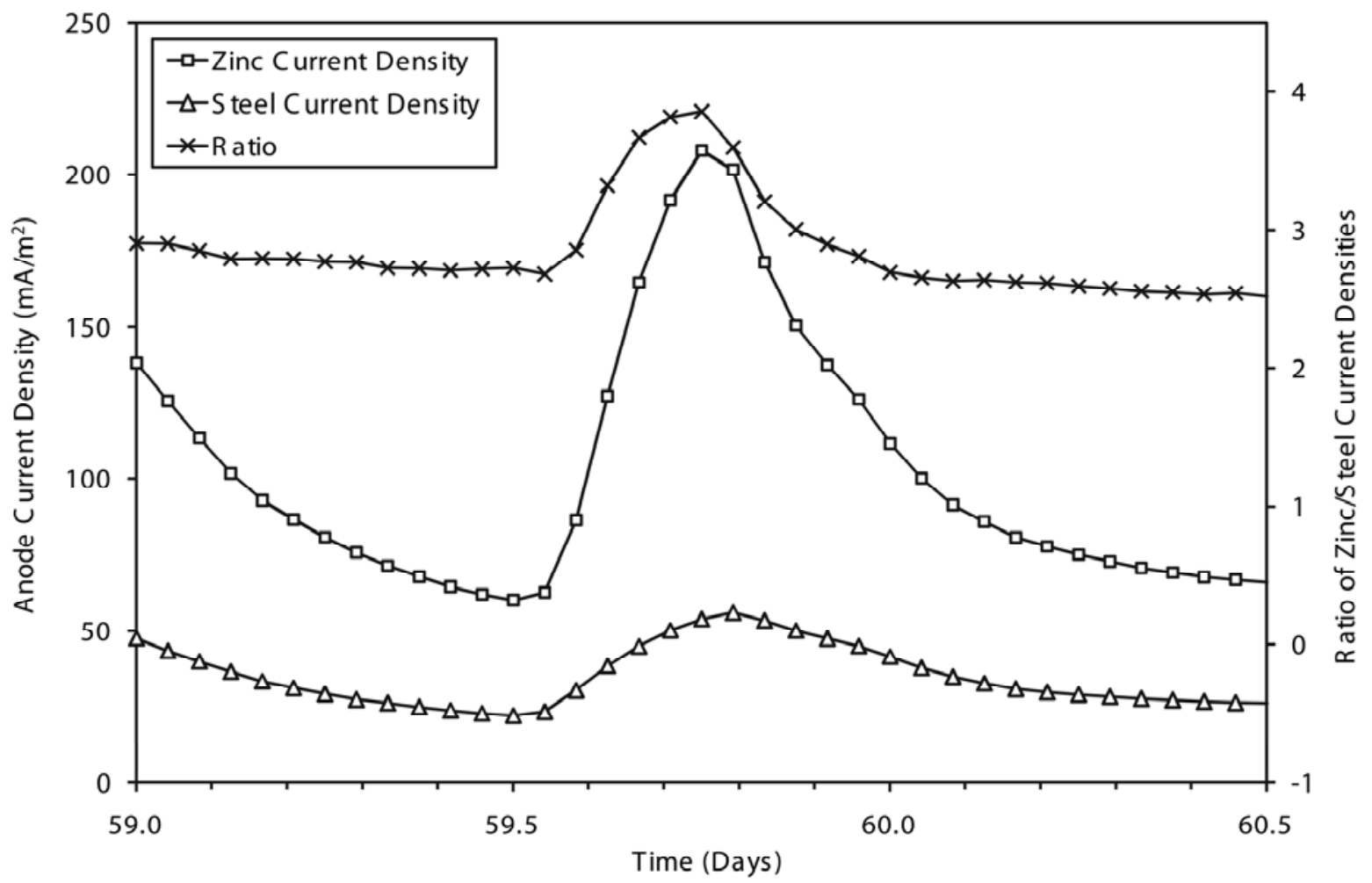

Figure 4. The zinc and steel anode current density response to dry weather and the resulting effect on the protective ratio.

\section{DISCUSSION}

In this work the zinc anode represents a galvanic anode installed in contaminated concrete and the steel anode represents a section of corroding steel rebar. The current density recorded for the steel anode gives an indication of the amount of corrosion activity occurring on the steel bar and 
represents the steel corrosion risk, whilst the zinc anode galvanic current represents the protective current. In this work both the zinc and steel response to environmental conditions have been recorded.

\section{Responsive Behaviour}

The steel current density gives a good indication of the need for protective current. It can be seen in Figure 2 that as the concrete dries (between days 50 and 67), the steel and zinc anode current densities fall and the difference between them becomes smaller. The steel requires little protective current as the corrosion risk is low due to the resistance of the drying concrete. In this state, little current is required to adequately protect the steel from corrosion.

On day 67 rainfall greatly reduced the resistance of the concrete, causing a significant increase in the steel corrosion current and an order of magnitude increase in the protective current. In this state the steel requires more protective current in order to maintain passivity as the reduction in overall concrete resistivity reduces the restriction on ionic flow and increases the corrosion risk. In this state, increased current is required to fully protect the steel. It can be seen that the installed zinc anode responds to the environment-related requirement for protective current.

Current output from the zinc anode responds to changes in the aggressive nature of the environment, passing a high current when required to address a high steel corrosion risk (signified by increased steel anode current) and low current when there is a low steel corrosion risk.

\section{Theoretical considerations}

Available electrochemical treatments for corrosion mitigation ascribe to one of two approaches. Realkalisation [11] and Electrochemical Chloride Extraction [12] treatments aim to make the environment at the steel surface less aggressive by increasing the $\mathrm{pH}$ (by generating hydroxide), or removing aggressive chloride ions, thus re-instating passivity. They are termed temporary treatments because the treatment time is short compared to the period of the protection offered. Cathodic protection (galvanic or impressed current) is a long term treatment which aims to suppress the steel corrosion reactions by permanently polarising the steel reinforcement [13]. A common protection criterion applied to cathodic protection systems [1] suggests that a $100 \mathrm{mV}$ steel depolarisation is required on disconnection of the anode system.

The concept of adequate polarisation requires the potential to be depressed below the pitting potential to prevent corrosion initiation. The pitting potential depends on factors such as concrete chloride content, so the use of cathodic protection as a corrosion prevention technique is associated with the pitting potential of reinforcing steel at some future chloride content. Because of this, it has been argued that a much larger potential shift is required. Values of up to $400 \mathrm{mV}$ have been suggested $[4,14,15]$. The requirement for a potential shift of less than $100 \mathrm{mV}$ to signify protection has little support in the academic literature.

What is not adequately considered by this concept is that the removal of chloride and the generation of hydroxide under polarisation will raise the pitting potential and hence reduce the magnitude of what constitutes adequate polarisation. This makes the protective effect of adequate polarisation a variable that is primarily determined by chloride removal and hydroxide generation, depending on which factor is dominant.

A protective effect based on the generation of hydroxide under an applied current has been termed Pit Re-alkalisation [16]. The effects of pit re-alkalisation, chloride extraction from pits and polarisation have been compared by others and on balance pit re-alkalisation and $\mathrm{pH}$ maintenance 
appear to be the dominant protective effects at typical cathodic protection current densities [17]. Indeed brief high current treatments have been shown to raise the chloride threshold level for corrosion initiation to values substantially greater than $2 \%$ chloride by weight of cement [5]. It is postulated that this is due to the generation of hydroxide at the steel.

The perceived need for polarisation inhibits the use of responsive behaviour. Current controlled power-supplies are predominantly used in Impressed Current Cathodic Protection systems to suppress current fluctuations in order to maintain consistent polarisation levels [18]. Another example is the suggestion that galvanic anode systems should only be applied in aggressive environments [19-21], because it is only in this environment that they can deliver sufficient current to meet the $100 \mathrm{mV}$ criteria.

As shown in the present work, steel in benign concrete environments does not corrode and therefore requires no protective current. This is consistent with a system based on the protective effects of pit re-alkalisation and $\mathrm{pH}$ maintenance. Steel in aggressive environments does corrode, and protective current is required to either restore a high $\mathrm{pH}$ at the site of a pit or prevent a local $\mathrm{pH}$ reduction and hence pit formation. The protection offered by pit re-alkalisation and $\mathrm{pH}$ maintenance depends on the present level of corrosion risk rather than the future risk. A cathodic protection system based on pit re-alkalisation and $\mathrm{pH}$ maintenance can fully utilise galvanic anode responsive behaviour.

\section{Environmental 'Shock'}

Figure 3 uses data from Figure 2 to show the zinc and steel anode current response to significant rainfall after a period of dry weather. This preliminary data suggests that the zinc anode responds more rapidly than the steel anode to the large increase in corrosion risk arising from 'environmental shock', in this case, rainfall. Such a feature would ensure that the protective current is greatly increased prior to any increased demand from the steel. It is postulated that the quicker response to corrosion risk by the zinc anode is due to the nature of the corrosion products which surround the two different materials, whose conductivity will dictate the speed of the anode response to changes in moisture content. Another explanation is that the polarising effect of the zinc anode slowed the response of the steel anode, thus contributing to the apparent rapid response of the zinc anode. The disparity in the anode response means that there is a dramatic increase in the 'protective ratio' (the difference between the zinc and steel current output) and therefore the amount of protection offered by the zinc. As the steel corrosion risk increased, the ratio stabilised at a more typical level.

In the absence of rain, the peak seen in Figure 4 is predominantly related to the temperature rise and fall during daylight hours. The data clearly shows that when the concrete environment is more aggressive (the temperature is higher) the zinc anode provides more protection to the steel although due to the more gradual changes in conditions there is no advanced response from the zinc. Even in relatively benign conditions (low temperature and dry concrete), the zinc responds to changes in corrosion risk.

\section{Practical Considerations}

As the current passed by the anodes is directly related to their consumption and therefore lifespan, Figure 2 demonstrates how anode life is conserved when the concrete environment is benign (during periods of little or no rain) and how it is shortened when conditions become more aggressive. It also shows that having an active anode surface is the key to obtaining adequate protection as the zinc anode is able to increase its current output dramatically as soon as the concrete environment becomes more aggressive. 
The sole sample for the work (Figure 1) had a unique design and was specially made to investigate the relationship between fluctuations in corrosion risk and galvanic anode current output. It was not designed with the intention of using the zinc anode to protect the steel anode from corrosion. Further tests on replicate samples are underway to corroborate the data collected, although observations from both site and laboratory installations $[9,10,22]$ reinforce the results presented.

\section{CONCLUSIONS}

1. It is shown for the first time that the current output of a zinc anode corresponds to the steel corrosion current in the same changing concrete environment. A high current is passed when required to address a high steel corrosion risk and a low current is passed when there is a low steel corrosion risk. This is termed responsive behaviour of the galvanic protection current.

2. A basis for using the responsive behaviour of galvanic anodes is provided by the protective effects of pit re-alkalisation and $\mathrm{pH}$ maintenance. In benign environments no current is required to achieve pit re-alkalisation or maintain the $\mathrm{pH}$, whilst in aggressive environments current is required to either restore a high $\mathrm{pH}$ at the site of a pit or prevent a local $\mathrm{pH}$ reduction and hence pit formation. The required protection current depends on the present level of corrosion risk. By contrast, protection based on achieving adequate polarisation inhibits the use of responsive behaviour and galvanic anodes might only deliver adequate polarisation in aggressive environments.

3. Preliminary data indicates that a zinc anode responds to environmental 'shock' events more rapidly than a steel anode, meaning that the protective current being passed to the steel is greatly increased just prior to increased corrosion risk. Postulated reasons include the higher conductivity of the zinc corrosion products or the polarising effect of the zinc anode causing a delay in the steel response to the increased corrosion risk.

4. The Pit Re-alkalisation/pH Maintenance hypothesis provides a basis for achieving corrosion protection with less integrated current (charge) than theories based on adequate polarisation. Responsive behaviour means that anode life is conserved in benign environments as the charge passed is less and therefore less anode material is consumed. This supports the conclusions of previous work.

\section{REFERENCES}

[1] British Standard BS EN 12696:2000, Cathodic Protection of Steel in Concrete, British Standards Institution, 1999.

[2] G.K. Glass, A.C. Roberts, N. Davison, Hybrid corrosion protection for chloride contaminated concrete, Construction Materials 161 (2008) 163-172.

[3] C. Christodoulou, G. Glass, J. Webb, S. Austin, C. Goodier, Assessing the long term benefits of Impressed Current Cathodic Protection, Corrosion Science 52 (2010) 2671-2679

[4] F.J. Presuel-Moreno, A.A. Sagues, S.C. Kranc, Steel activation in concrete following interruption of long term cathodic polarisation, CORROSION 2002, Houston, Texas, (Paper No. 02259).

[5] G.K. Glass, B. Reddy, L. Clark, Making reinforced concrete immune from chloride corrosion, Proceedings Institution Civil Engineers, Construction Materials, 160 (2007) 155-164. 
[6] G.K. Glass, N. Davison, A.C. Roberts, Hybrid Electrochemical Treatment in the Repair of Corrosion Damaged Concrete, Concrete Platform 2007, Queens University, Belfast, April 2007.

[7] G.K. Glass, N.R. Buenfeld, The inhibitive effects of electrochemical treatment applied to steel in concrete, Corrosion Science 42, 6, (2000) 923-927.

[8] G.K. Glass, N. Davison, A.C. Roberts, Pit realkalisation and its role in the electrochemical repair of reinforced concrete, Cathodic Protection Conference, University of Manchester, 2006.

[9] S.P. Holmes, G.K. Glass, A.C. Roberts, P. Robins, G.D. Wilcox, the response of protective current to environmental conditions during hybrid anode concrete repair treatments, CORROSION 2011, Houston, Texas (Paper no. 19132).

[10] S.P. Holmes, The response of galvanic protection current to environmental changes, EUROCORR 2009, Nice, France (Paper no. 8254).

[11] J. P. Broomfield, Electrochemical Realkalisation of Steel Reinforced Concrete - A State of the Art Report, Corrosion Prevention Association Technical Note No: 9, 2005.

[12] J.C. Orellan, G. Escadeillas, G. Arliguie, Effectiveness and structural implications of electrochemical chloride extraction from reinforced concrete beams, Cement and Concrete Research 34 (2004) 227-234.

[13] J.P.Broomfield, Corrosion of Steel in Concrete, understanding, investigation and repair, E \& F Spon, London, 1997.

[14] J. P. Broomfield, The Principles and Practice of Galvanic Cathodic Protection for Reinforced Concrete, Corrosion Prevention Association Technical Note No: 6, 2005.

[15] K. Takewaka, Cathodic protection for reinforced-concrete and prestressed-concrete structures, Corrosion Science 35, 5-8, (1993) 1617-1626.

[16] G. K. Glass, N. Davison, A. C. Roberts, Pit re-alkalisation and its role in the electrochemical repair of reinforced concrete, The Journal of Corrosion Science and Engineering 9 (2007) Paper 10.

[17] G.K. Glass, A.C. Roberts, N. Davison, Hybrid corrosion protection for chloride contaminated concrete, Construction Materials 161 (2008) 163-172.

[18] A. A. Sagues, M. Dugarte, Galvanic Point Anodes for Extending the Service Life of Patched Areas Upon Reinforced Concrete Bridge Members, Florida Department of Transportation, Report No. BD544-09, 2009.

[19] A. A. Sagues, R. G. Powers, Sprayed Zinc Galvanic Anodes for Concrete Marine Bridge Substructures, Strategic Highway Research Program Report No. SHRP-S-405, 1994.

[20] H. McArthur, S. D'Arcy, J. Barker, Cathodic protection by impressed DC currents for construction, maintenance and refurbishment in reinforced concrete, Construction and Building Materials 7, 2, (1993) 85-93. 
[21] O. T. De Rincon, Y. Hernandez Lopez, A. de Valle-Moreno, A. A. Torres-Acosta, F. Barrios, P. Montero, P. Oidor-Salinas, J. R. Montero, Environmental influence on point anodes performance in reinforced concrete, Construction and Building Materials 22 (2008), 494-503.

[22] S.P. Holmes, G. D. Wilcox, P. J. Robins, G. K. Glass, A. C. Roberts, Long term assessment of a hybrid electrochemical treatment, Materials and Corrosion (2011), Available online 01/06/11. 